\title{
Evaluation of Effect of Brassinolide in Brassica juncea Leaves under Drought Stress in Field Conditions
}

\author{
Naveen Naveen ${ }^{1}$, Nisha Kumari ${ }^{1, *}{ }^{6}$, Ram Avtar ${ }^{2}\left(\mathbb{D}\right.$, Minakshi Jattan $^{3}$, Sushil Ahlawat ${ }^{4}$, Babita Rani ${ }^{1}$, \\ Kamla Malik ${ }^{5}$, Anubhuti Sharma ${ }^{6}$ and Manjeet Singh ${ }^{2, *(D)}$ \\ 1 Department of Biochemistry, CCS Haryana Agricultural University, Hisar 125004, Haryana, India; \\ jangranaveen4321@gmail.com (N.N.); babitachahalkharb@gmail.com (B.R.) \\ 2 Oilseeds Section, Department of Genetics and Plant Breeding, CCS Haryana Agricultural University, \\ Hisar 125004, Haryana, India; ramavtar0706@gmail.com \\ 3 Cotton Section, Department of Genetics and Plant Breeding, CCS Haryana Agricultural University, \\ Hisar 125004, Haryana, India; jattanmina@gmail.com \\ 4 Department of Entomology, CCS Haryana Agricultural University, Hisar 125004, Haryana, India; \\ sushilahlawat08@gmail.com \\ 5 Department of Microbiology, CCS Haryana Agricultural University, Hisar 125004, Haryana, India; \\ kamlamalik06@gmail.com \\ 6 ICAR-Directorate of Rapeseed-Mustard Research, Sewar, Bharatpur 321303, Rajasthan, India; \\ sharmaanubhuti98@gmail.com \\ * Correspondence: nishaahlawat211@gmail.com (N.K.); manjeetsingh125033@gmail.com (M.S.); \\ Tel.: +91-9468117723 (N.K.); +91-9053127937 (M.S.)
}

\section{check for} updates

Citation: Naveen, N.; Kumari, N.; Avtar, R.; Jattan, M.; Ahlawat, S.; Rani, B.; Malik, K.; Sharma, A.; Singh, M. Evaluation of Effect of Brassinolide in Brassica juncea Leaves under Drought Stress in Field Conditions. Horticulturae 2021, 7, 514. https://doi.org/10.3390 /horticulturae7110514

Academic Editors: Xiaowu Wang, Jian Wu and Xu Cai

Received: 7 September 2021

Accepted: 17 November 2021

Published: 22 November 2021

Publisher's Note: MDPI stays neutral with regard to jurisdictional claims in published maps and institutional affiliations.

Copyright: (c) 2021 by the authors Licensee MDPI, Basel, Switzerland. This article is an open access article distributed under the terms and conditions of the Creative Commons Attribution (CC BY) license (https:// creativecommons.org/licenses/by/ $4.0 /)$.

\begin{abstract}
Drought stress is considered to be a major factor responsible for reduced agricultural productivity, because it is often linked to other major abiotic stresses, such as salinity and heat stress. Understanding drought-tolerance mechanisms is important for crop improvement. Moreover, under drought conditions, it is possible that growth regulators are able to protect the plants. Brassinosteroids not only play a regulatory role in plant growth, but also organize defense mechanisms against various tresses. This study aimed to evaluate the effect of brassinolide on physio-biochemical amendment in two contrasting cultivars (drought-tolerant RH 725, and drought-sensitive RH 749) of Brassica juncea under drought stress. Two foliar sprayings with brassinolide (10 and $20 \mathrm{mg} / \mathrm{L})$ were carried out in both cultivars (RH 725 and RH 749) at two stages-i.e., flower initiation, and 50\% flowering-under stress conditions. The results clearly revealed that the activities of antioxidative enzymes and non-enzymatic antioxidants (carotenoids, ascorbic acid, and proline) increased significantly in RH 725 at $50 \%$ flowering, whereas $20 \mathrm{mg} / \mathrm{L}$ of brassinolide showed the most promising response. The different oxidative stress indicators (i.e., hydrogen peroxide, malondialdehyde, and electrolyte leakage) decreased to a significant extent at $20 \mathrm{mg} / \mathrm{L}$ of brassinolide spray in RH 725 at $50 \%$ flowering. This study indicates that brassinolide intensifies the physio-biochemical attributes by improving the antioxidant system and photosynthetic efficiency in RH 725 at $50 \%$ flowering. It is assumed that enhanced production of proline, improvement of the antioxidant system, and reduction in the amount of stress indicators impart strength to the plants to combat the stress conditions.
\end{abstract}

Keywords: antioxidants; Brassica juncea; brassinolide; drought stress; proline

\section{Introduction}

Rapeseed mustard comprises an important group of oilseed Brassica crops. In this group, Indian mustard [Brassica juncea (L.) Czern \& Coss.] is an important edible, oilyielding crop covering about $90 \%$ of the cultivated area under brassica oilseeds in India [1]. It is the third-largest source of vegetable oil in the world, after soybeans and palm oil. Indian mustard has the potential for quicker seed germination, high productivity, and heat and drought tolerance, along with enhanced insect and disease resistance if sown on time [2], whereas late sowing exposes the crop to abiotic and biotic stresses. There is a dire 
need to intensify in the production of food crops but, on the other hand, environmental stresses (biotic and abiotic) suppress the overall yield of agricultural crops. Drought stress is recognized as the main factor leading to the decline in agricultural productivity, because drought is persistently related to other major abiotic stresses, such as high-temperature stress and salinity [3]. It is estimated that by the end of the 21st century, the proportion of drought-prone areas will have doubled.

Reactive oxygen species (ROS) are continuously generated in plant mitochondria, plastids, peroxisomes, apoplasts, and cytosol as byproducts of different cellular metabolic pathways, and they hinder photosynthesis. The enhanced production of alkoxy radicals $\left(\mathrm{RO}^{-}\right)$, superoxide radicals $\left(\mathrm{O}^{2-}\right)$, perhydroxy radicals $\left(\mathrm{HO}^{2-}\right)$, hydrogen peroxide $\left(\mathrm{H}_{2} \mathrm{O}_{2}\right)$, singlet oxygen $\left({ }_{1} \mathrm{O}^{2}\right)$, and hydroxyl radicals $\left(\mathrm{OH}^{-}\right)$is a common end result of plant-rearing under different abiotic stresses $[4,5]$. The production of reactive oxygen species is the basis for oxidative stress, damaging plants by oxidizing membrane lipids, nucleic acids, proteins, and photosynthetic pigments [6]. The ROS hamper the plants' photosynthesis and enzymes of the Calvin cycle, altering chlorophyll components and causing damage to the photosynthetic apparatus [7]. To survive under such intense environmental conditions, and to increase their tolerance, plants have developed many intricate defense mechanisms. Stress tolerance in plants necessitates the activation of complex metabolic activities, including antioxidative pathways-especially ROS-scavenging systems within the cells that, in turn, can contribute to continued plant growth under stress conditions [8]. The different antioxidative enzymes in plants-such as superoxide dismutase (SOD), catalase (CAT), and peroxidase (POX) — scavenge these ROS molecules [9]; however, oxidative stress is generated in plants if there is an imbalance in ROS [10]. The resistance to oxidative stress relies on the overall balance between the fabrication of ROS and the antioxidant capability of the cells [11].

The drought-tolerance mechanism in plants also includes some plant growth regulators and secondary metabolites, such as auxin, abscisic acid (ABA), jasmonic acid, plant steroids, and ethylene. Among the variety of compounds used to alleviate plant stress, brassinosteroids (BRs) are considered to be plant hormones that regulate plant growth and productivity. Brassinosteroids (BRs) are polyhydroxylated steroidal plant hormones that play an essential role in the regulation of plant growth and development processes. Myriad studies have highlighted that these are crucial for regulating a range of physiological processes, such as cell proliferation, expansion, male fertility, senescence, leaf development, and vascular differentiation. These compounds have a wide range of biological activities, providing unique possibilities to increase crop yields by altering plant metabolism and protecting plants from environmental stresses [12]. The research conducted thusfar shows that BRs cause a wide range of morphological and physiological responses in plants $[13,14]$. In addition, BRs are known as regulators of transcription and translation mechanisms, by which they improve the levels of total proteins and enzymes [15], as well as increasing the seed yield at harvest [16]. BRs not only play a regulatory role in plant growth, but also participate in the establishment of defense mechanisms to deal with various biotic and abiotic stresses [13]. Several BRs with brassinolide as the main component have been evaluated in the field, and they have significantly increased crop yields. Exogenous application of BRs has improved tolerance to salinity [17], drought [16,18], high/low temperatures, and heavy metals [13]. There are few reports on the role of brassinosteroids in the unveiling of genes and metabolic pathways that confer drought resistance to Indian mustard [16]. However, the data that are currently available on the role of BRs in plant drought response, from the few studies that have been performed with genotypes of known drought sensitivity, are not very conclusive [19-21]. Any comparison of the impact of exogenously applied BRs on drought-tolerant/sensitive genotypes should reveal the BR-induced changes-particularly in the sensitive genotypes, because the tolerant genotypes should experience less intensive drought effects. This should be similar to the situation observed for BRs exogenously applied to plants exposed to drought ranging from mild/moderate to less intense; BRs always have a greater effect on more strongly stressed plants. There have also been some 
cases where the drought-tolerant genotype showed a more pronounced response to BRs than the drought-sensitive one, as has been reported in several previous studies. Thus, the situation is not so simple, and probably depends on plant species as well as on a mechanism that is responsible for the drought resistance/sensitivity of the respective genotype. In this context, the present study was designed with the objectives to address the following questions: (1) whether exogenous application of BRs could alleviate drought stress in Indian mustard, and (2) whether the drought-tolerant and drought-sensitive cultivars have similar responses to these treatments under drought stress.

\section{Materials and Methods}

\subsection{Plant Materials}

Two Indian mustard [Brassica juncea (L.) Czern \& Coss.] cultivars-drought-tolerant (RH 725) and drought-sensitive (RH 749)—were used in this study. The two cultivars were sown in the Research Farm of Oilseeds Section, Department of Genetics and Plant Breeding, CCS Haryana Agricultural University, Hisar, in a randomized complete block design (RCBD) with three replications. The CCS HAU, Hisar, is situated at a latitude of $29^{\circ} 10^{\prime} \mathrm{N}$, longitude of $75^{\circ} 46^{\prime} \mathrm{E}$, and altitude $215.2 \mathrm{~m}$ above main sea level, and falls in the semi-tropical region of the western zone of India. Drought conditions were achieved by withholding irrigation from the crop. The weather data (rainfall) during crop season are presented in Supplementary Table S1, which shows that rainfall was negligible during the crop-growing period and the drought conditions were adequate for this study. Two foliar sprayings of brassinolide at 10 and $20 \mathrm{mg} / \mathrm{L}$ concentrations were carried out in both of the cultivars at two growth stages-i.e., flower initiation (42 days after sowing; DAS) and 50\% flowering (52 DAS) — with water spray as a control. All physio-biochemical analysis was carried out on leaves, which were taken two days after each spray.

\subsection{Physiological Parameters}

Parameters such as photosynthetic rate, stomatal conductance, and transpiration rate were measured using an infrared gas analyzer (IRGA) system (LI-COR USA Model LI6400, LE, USA) as per the method employed by Silva et al. [22], and their corresponding units are as follows: photosynthetic rate $\left(\mathrm{PR}, \mu \mathrm{mol} \mathrm{CO} \mathrm{Cm}^{-2} \mathrm{~s}^{-1}\right)$, stomatal conductance (SC, mole $\mathrm{H}_{2} \mathrm{O} \mathrm{m}^{-2} \mathrm{~s}^{-1}$ ), and transpiration rate (TR, mmol $\mathrm{H}_{2} \mathrm{O} \mathrm{m}^{-2} \mathrm{~s}^{-1}$ ).

\subsection{Enzyme Extraction and Assay}

Leaves of both cultivars of $B$. juncea, after two days of each spray, were used for enzymatic studies. Extraction was carried out at $4{ }^{\circ} \mathrm{C}$, and standardized extraction conditions with respect to the molarity and $\mathrm{pH}$ of the buffer were maintained in order to achieve maximum enzyme activity. One gram of leaf sample was macerated in a chilled pestle and mortar in the presence of $4 \mathrm{~mL}$ of $0.1 \mathrm{M}$ potassium phosphate buffer $(\mathrm{pH} 7.0)$. The homogenate was centrifuged at $12,000 \times \mathrm{g}$ rpm for $30 \mathrm{~min}$ in a refrigerated centrifuge at $4{ }^{\circ} \mathrm{C}$. The supernatant was carefully decanted and used for the enzyme assay.

The SOD activity was determined by quantifying the ability of the enzyme to inhibit the photochemical reduction of nitro blue tetrazolium (NBT) to formazan [23]. One enzyme unit was defined as the amount of enzyme that could cause $50 \%$ inhibition of the photochemical reaction. The catalase activity was measured by following the method of Sinha [24]. One unit of enzyme activity was defined as the amount of enzyme required to consume $1 \mu \mathrm{mol} \mathrm{H}_{2} \mathrm{O}_{2}$ per minute under assay conditions. The POX activity was assayed by adopting the method of Shannon et al. [25]. One unit of enzyme activity was equivalent to one $\mu \mathrm{mol}$ of $\mathrm{H}_{2} \mathrm{O}_{2}$ oxidized per minute.

\subsection{Non-Enzymatic Estimations}

For extraction of carotenoids, $30 \mathrm{mg}$ of the fresh leaves was cut into small discs and dipped in test tubes containing $3 \mathrm{~mL}$ of dimethyl sulfoxide (DMSO). The tubes were kept at room temperature overnight. The carotenoids extracted in the DMSO were estimated by 
the method of Hiscox and Israelstam [26]. Ascorbic acid was extracted from the leaves via homogenization in $5 \mathrm{~mL}$ of $5 \%(w / v)$ metaphosphoric acid in glacial acetic acid, and the homogenate was centrifuged at $10,000 \times g \mathrm{rpm}$ for $25 \mathrm{~min}$. The supernatant thus obtained was used for the estimation of ascorbic acid. Ascorbic acid content was estimated by the method of Roe [27]. For proline estimation, $1 \mathrm{~g}$ of tissue was homogenized in $5 \mathrm{~mL}$ of sulfosalicylic acid (3\%) and centrifuged at $10,000 \times g$ rpm for $25 \mathrm{~min}$; the supernatant thus obtained was used for the estimation of proline content. Proline content was estimated by using the method of Bates et al. [28].

\subsection{Extraction and Estimation of Oxidative Stress Indicators}

For the extraction of $\mathrm{H}_{2} \mathrm{O}_{2}$ and MDA, $1.0 \mathrm{~g}$ of leaves from each treatment was taken and ground in $6 \mathrm{~mL}$ of chilled $0.8 \mathrm{~N} \mathrm{HClO}_{4}$ and centrifuged at $10,000 \times \mathrm{g} \mathrm{rpm}$ for $30 \mathrm{~min}$. The clear supernatant thus obtained was used for further estimation. Hydrogen peroxide was estimated by the method of Sinha [24]. Malondialdehyde was estimated according to the method of Heath and Packer [29].The relative intactness of the plasma membrane was measured as the leakage percentage of electrolytes, as described by Gong et al. [30].

\subsection{Statistical Analysis}

Three-way ANOVA was applied to test the statistical significance of the treatments. Duncan'smultiple range test (DMRT) was applied for multiple comparisons of treatments' mean values. Pearson's product-moment correlation was used to test the relationships between the antioxidant parameters. All statistical analyses were performed using the OP STAT statistical software developed by CCS HAU, Hisar, India. Graphs were prepared using Microsoft Excel, 2013.

\section{Results}

\subsection{Physiological Parameters}

The stomatal conductance, photosynthetic rate, and transpiration rate were significantly influenced by cultivar, growth stage, brassinolide concentration, and their interactions (Table 1). The brassinolide foliar application $(10$ and $20 \mathrm{mg} / \mathrm{L})$ increased the stomatal conductance, photosynthetic rate, and transpiration rate, and these increases had the greatest statistical significance in the drought-tolerant cultivar RH 725 as compared to drought-sensitive RH 749 at both the growth stage and the 50\% flowering stage. The photosynthetic parameters at the $50 \%$ flowering stage were high with brassinolide (10 and $20 \mathrm{mg} / \mathrm{L}$ ) spray in both cultivars (RH 725 and RH 749). Brassinolide (20 mg/L) enhanced the stomatal conductance, photosynthetic rate, and transpiration rate by $47.16,40.92$, and $31.06 \%$ at the flower initiation stage and $50.72,46.04$, and $33.76 \%$ at the $50 \%$ flowering stage, respectively, in RH 725. This enhancement was low in drought-sensitive RH 749 as comparison to drought-tolerant RH 725 (Figures 1-3).

Table 1. Analysis of variance in the effects of cultivars (C), sampling time points (ST), and different brassinolide concentrations (BC), as well as their interactions, on the superoxide dismutase activity (SOD), peroxidase activity (POX), catalase activity (CAT), ascorbic acid (ASA), proline (PRO), carotenoids (CC), hydrogen peroxide $\left(\mathrm{H}_{2} \mathrm{O}_{2}\right)$, and malondialdehyde (MDA) content, as well as electrolyte leakage (EL), stomatal conductance (SC), photosynthetic rate (PR), and transpiration rate (TR).

\begin{tabular}{|c|c|c|c|c|c|c|c|c|c|c|c|c|c|}
\hline \multirow{2}{*}{ sv } & \multirow{2}{*}{ Df } & \multicolumn{12}{|c|}{ Mean Squares } \\
\hline & & SOD & POX & CAT & ASA & PRO & CC & $\mathrm{H}_{2} \mathrm{O}_{2}$ & MDA & EL & $\mathrm{sC}$ & PR & TR \\
\hline $\mathrm{C}$ & 1 & 1335.17 ** & $61.96 * *$ & $27,408.11$ ** & $1333.49 * *$ & $26.87 * *$ & $22.14 * *$ & $38,037.56^{* *}$ & $59.50 * *$ & 225.91 ** & $0.65 * *$ & $147.87 * *$ & $5.48 * *$ \\
\hline ST & 1 & 1400.01 ** & 18.30 ** & 6702.90 ** & $2295.71 * *$ & 46.10 ** & $18.16^{* *}$ & $24,628.80$ ** & $44.94^{* *}$ & 2334.83 ** & $0.29 * *$ & $98.01^{* *}$ & 59.78 ** \\
\hline $\mathrm{C} \times \mathrm{ST}$ & 1 & 190.35 ** & 0.40 & $88.59 * *$ & $19.90 * *$ & 0.61 & 0.79 & $150.79 * *$ & $8.05^{* *}$ & $8.17 * *$ & 0.01 ** & 12.39 ** & $0.08^{* *}$ \\
\hline BC & 2 & 137.58 ** & 31.86 ** & $5914.39 * *$ & 1068.52 ** & $11.94 * *$ & $7.58^{* *}$ & $18,979.63 * *$ & 178.78 ** & 242.52 ** & $0.14 * *$ & $98.06 * *$ & 6.72 ** \\
\hline $\mathrm{C} \times \mathrm{BC}$ & 2 & $14.73^{* *}$ & 1.79 & 320.08 ** & $33.10^{* *}$ & 0.51 & 0.47 & 178.68 ** & 0.84 & $4.07 *$ & $0.02 * *$ & $8.20^{* *}$ & 0.20 ** \\
\hline $\mathrm{ST} \times \mathrm{BC}$ & 2 & $15.35^{* *}$ & 0.48 & 192.53 ** & $6.57^{* *}$ & 0.63 & 0.48 & 124.60 ** & $5.13 * *$ & 1.26 & 0.01 ** & 2.13 ** & 0.54 ** \\
\hline $\mathrm{C} \times \mathrm{ST} \times \mathrm{BC}$ & 2 & $1.95 *$ & 0.01 & 2.95 * & 0.47 & 0.00 & 0.12 & $94.83^{* *}$ & 1.09 & 0.29 & 0.00 & 0.46 ** & $0.06^{* *}$ \\
\hline Error & 22 & 0.39 & 0.90 & 0.61 & 0.99 & 0.53 & 0.82 & 0.84 & 0.83 & 0.78 & 0.00 & 0.02 ** & $0.01^{* *}$ \\
\hline
\end{tabular}

** Significant at $p \leq 0.01 ;{ }^{*}$ significant at $p \leq 0.05$. 


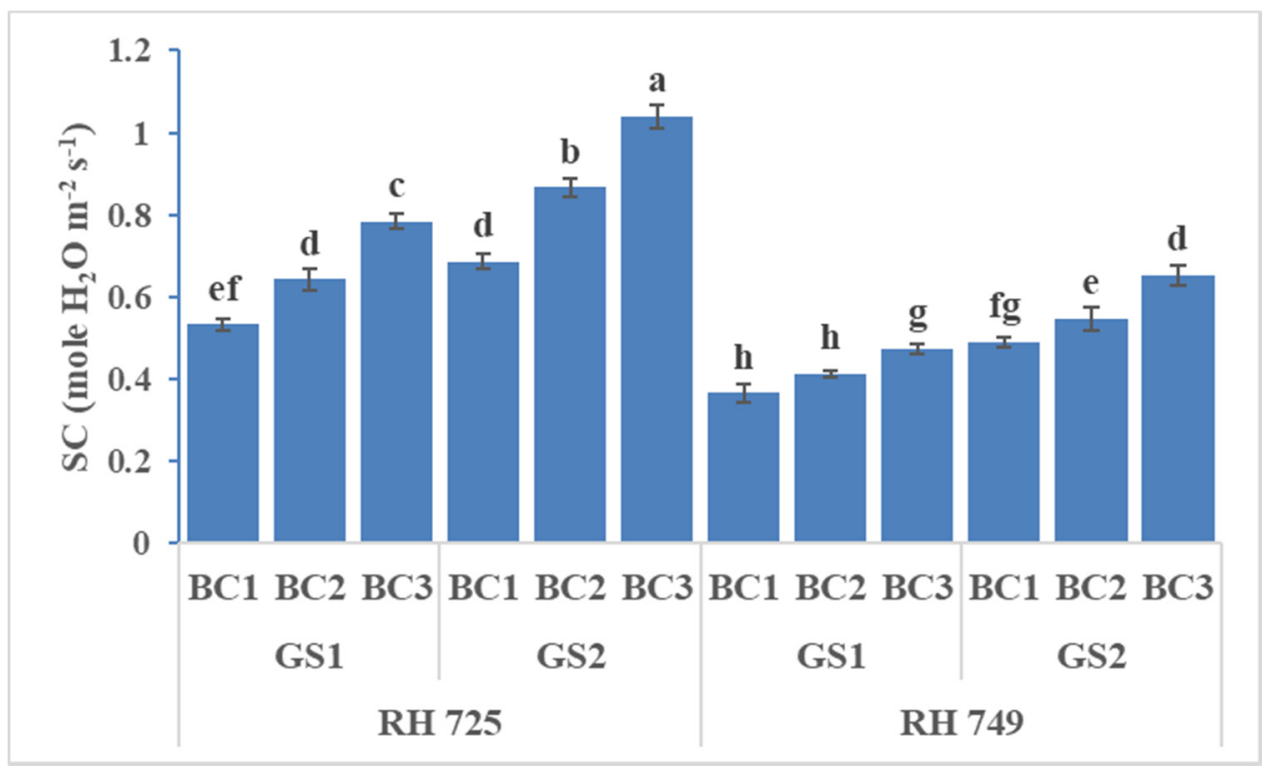

Figure 1. Comparisons of the effects of different concentrations of brassinolide sprays (BC1: control (water spray); BC2: $10 \mathrm{mg}$ BRs/L water; BC3: $20 \mathrm{mg}$ BRs/L water) on the stomatal conductance (SC) of drought-tolerant (RH 725) and drought-sensitive (RH 749) Indian mustard cultivars at the flower initiation (GS1) and 50\% flowering (GS2) stages. Columns marked by different letters indicate significant differences $(p<0.05)$ between treatments based on Duncan's multiple range test. Error bars denote the standard errors of the mean.

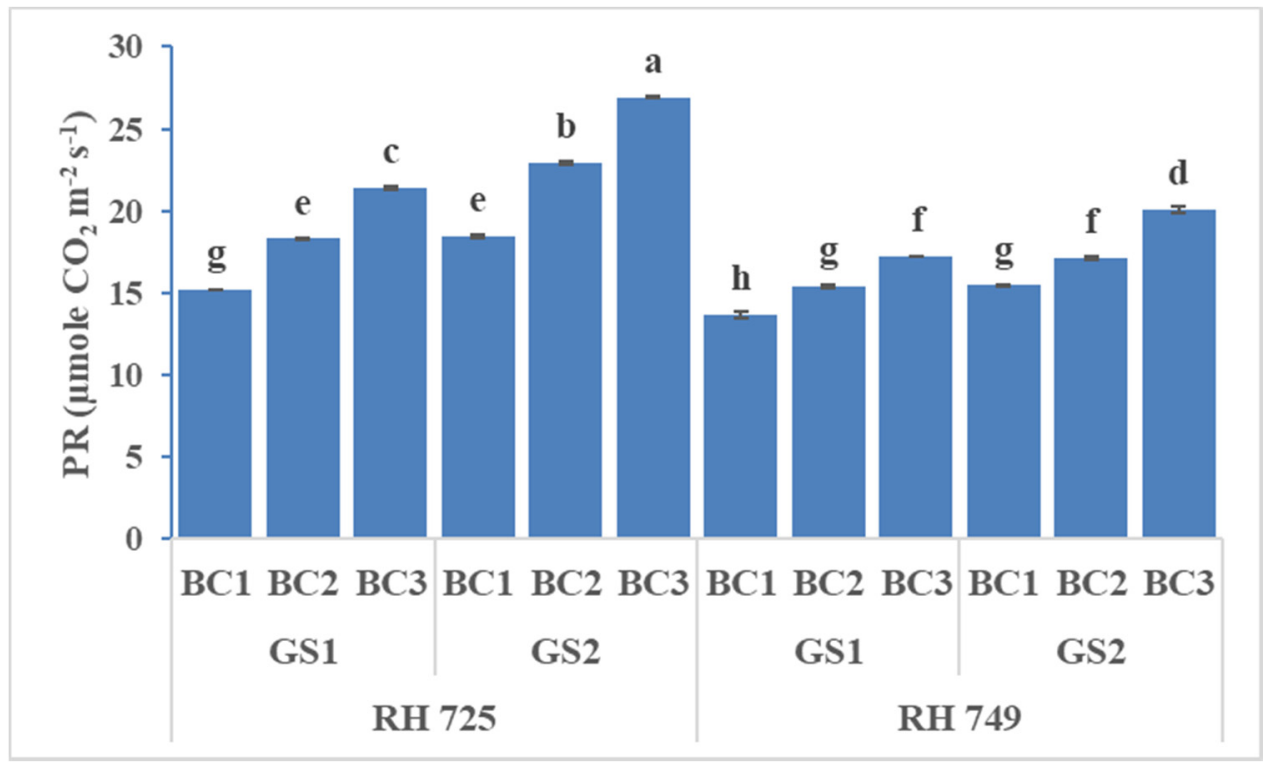

Figure 2. Comparisons of the effects of different concentrations of brassinolide sprays (BC1: control (water spray); BC2: $10 \mathrm{mg}$ BRs/L water; $\mathrm{BC} 3: 20 \mathrm{mg} \mathrm{BRs} / \mathrm{L}$ water) on the photosynthetic rate (PR) of drought-tolerant (RH 725) and drought-sensitive (RH 749) Indian mustard cultivars at the flower initiation (GS1) and 50\% flowering (GS2) stages. Columns marked by different letters indicate significant differences $(p<0.05)$ between treatments based on Duncan's multiple range test. Error bars denote the standard errors of the mean. 


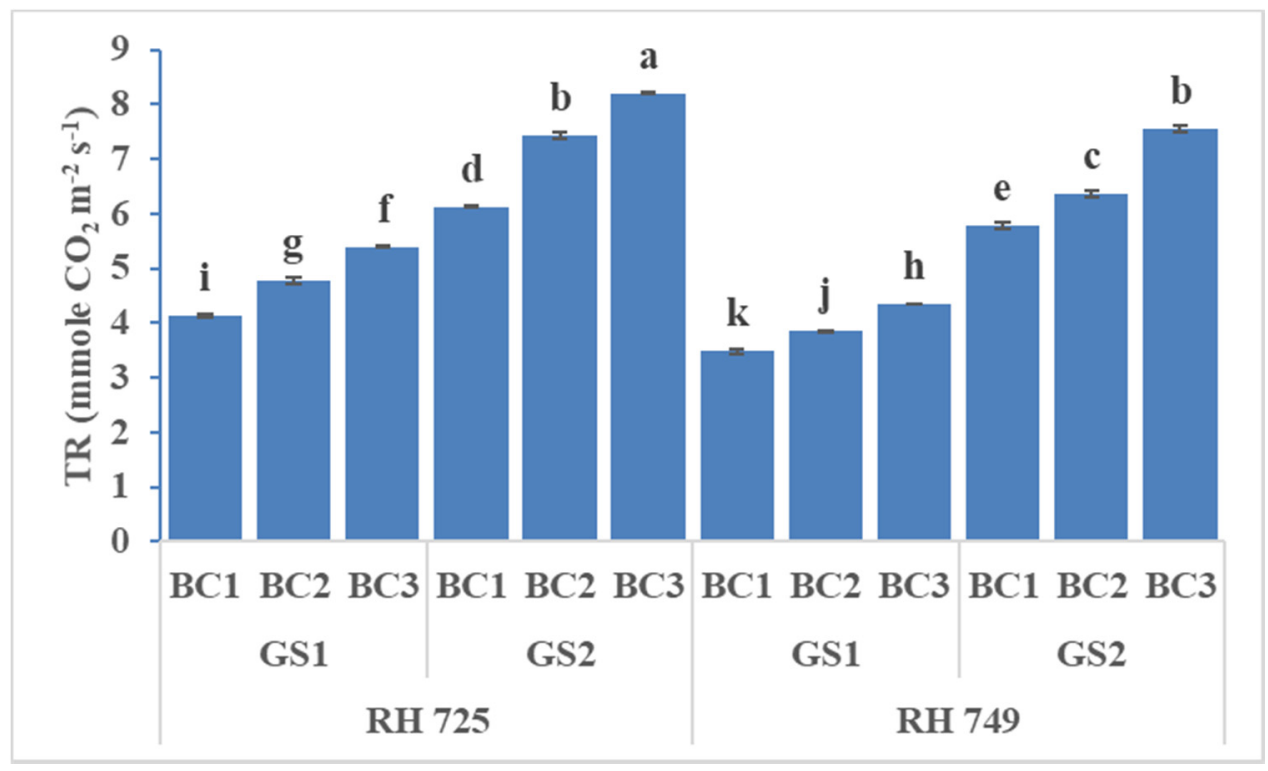

Figure 3. Comparisons of the effects of different concentrations of brassinolide sprays (BC1: control (water spray); BC2: $10 \mathrm{mg}$ BRs/L water; BC3: $20 \mathrm{mg}$ BRs/L water) on the transpiration rate (TR) of drought-tolerant (RH 725) and drought-sensitive (RH 749) Indian mustard cultivars at the flower initiation (GS1) and 50\% flowering (GS2) stages. Columns marked by different letters indicate significant differences $(p<0.05)$ between treatments based on Duncan's multiple range test. Error bars denote the standard errors of the mean.

\subsection{Oxidative Stress Indicators}

Three-way ANOVA (Table 1) showed highly significant effects of all the three individual factors and their interactions on oxidative stress indicators, except that $C \times B C$ and $\mathrm{C} \times \mathrm{GS} \times \mathrm{BC}$ were insignificant for malondialdehyde, while $\mathrm{GS} \times \mathrm{BC}$ and $\mathrm{C} \times \mathrm{GS} \times \mathrm{BC}$ were insignificant for electrolyte leakage. Figures $4-6$ show that brassinolide treatments significantly decreased the oxidative stress indicators-i.e., hydrogen peroxide $\left(\mathrm{H}_{2} \mathrm{O}_{2}\right)$, malondialdehyde (MDA), and electrolyte leakage (EL) - in Indian mustard. Brassinolide foliar application at $20 \mathrm{mg} / \mathrm{L}$ showed a maximum decrease in $\mathrm{H}_{2} \mathrm{O}_{2}, \mathrm{MDA}$, and EL over their respective controls at the $50 \%$ flowering stage of growth in RH 725. The percentage decrease in $\mathrm{H}_{2} \mathrm{O}_{2}, \mathrm{MDA}$, and EL caused by brassinolide ( $20 \mathrm{mg} / \mathrm{L}$ ) was $32.14,60.37$, and $37.94 \%$, respectively, in RH 725 at the 50\% flowering stage. On the other hand, at the same plant growth stage, this decrease was $18.56 \%, 54.98 \%$, and $20.68 \%$ in $\mathrm{H}_{2} \mathrm{O}_{2}, \mathrm{MDA}$, and $\mathrm{EL}$, respectively, at $20 \mathrm{mg} / \mathrm{L}$ in $\mathrm{RH} 749$, which was a sensitive cultivar. It is clear from these results that the tolerant cultivar RH 725 showed a significantly better response to brassinolide as compared to the sensitive cultivar RH 749. 


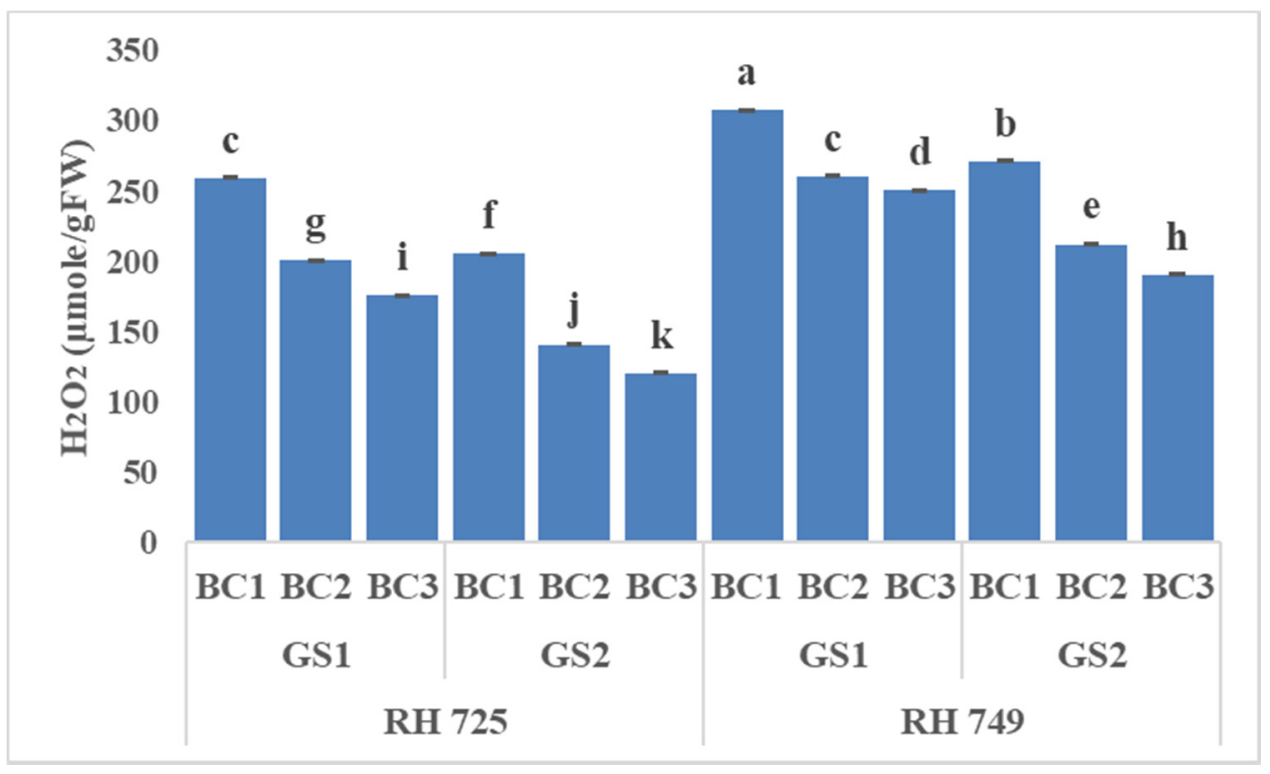

Figure 4. Comparisons of the effects of different concentrations of brassinolide sprays (BC1: control (water spray); $\mathrm{BC} 2: 10 \mathrm{mg} \mathrm{BRs} / \mathrm{L}$ water; $\mathrm{BC} 3: 20 \mathrm{mg} \mathrm{BRs} / \mathrm{L}$ water) on the hydrogen peroxidase $\left(\mathrm{H}_{2} \mathrm{O}_{2}\right)$ concentration of drought-tolerant ( $\left.\mathrm{RH} 725\right)$ and drought-sensitive ( $\left.\mathrm{RH} 749\right)$ Indian mustard cultivars at the flower initiation (GS1) and 50\% flowering (GS2) stages. Columns marked by different letters indicate significant differences $(p<0.05)$ between treatments based on Duncan's multiple range test. Error bars denote the standard errors of the mean.

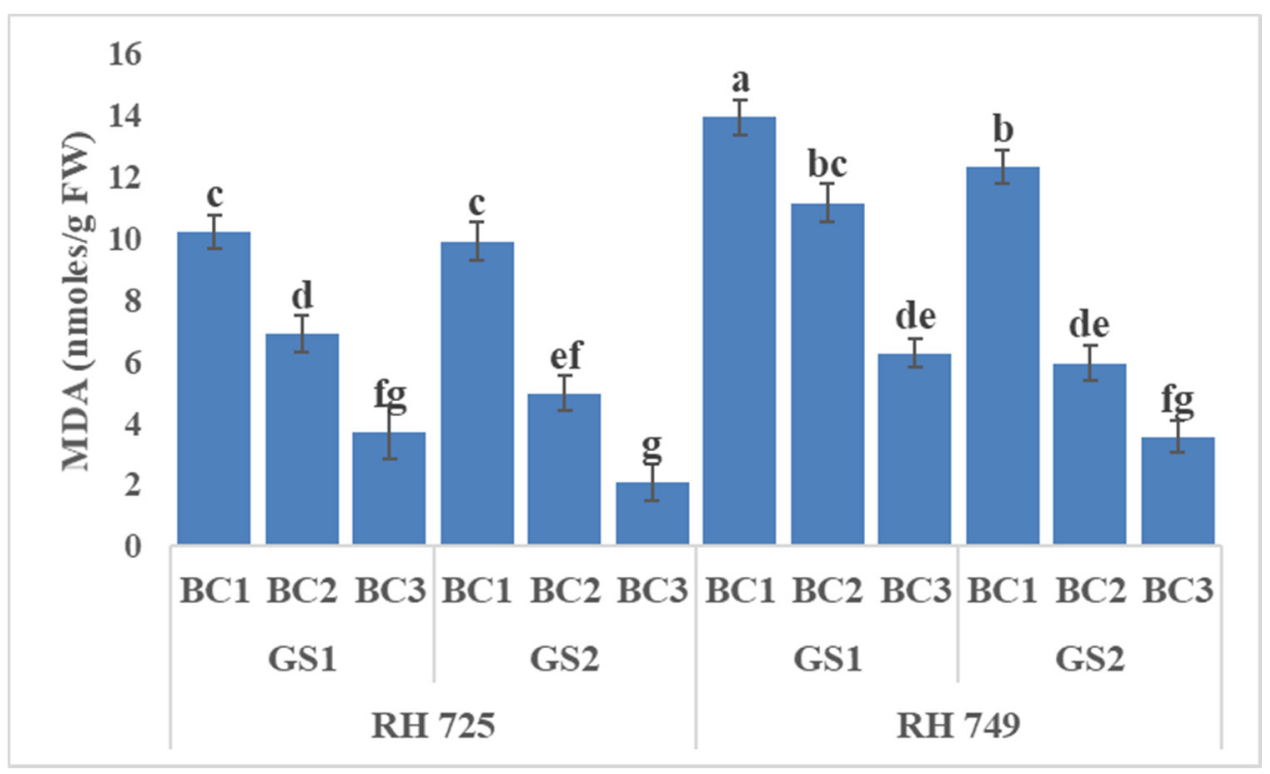

Figure 5. Comparisons of the effects of different concentrations of brassinolide sprays (BC1: control (water spray); BC2: $10 \mathrm{mg}$ BRs/L water; BC3: $20 \mathrm{mg}$ BRs/L water) on the malondialdehyde (MDA) concentration of drought-tolerant (RH 725) and drought-sensitive (RH 749) Indian mustard cultivars at the flower initiation (GS1) and 50\% flowering (GS2) stages. Columns marked by different letters indicate significant differences $(p<0.05)$ between treatments based on Duncan's multiple range test. Error bars denote the standard errors of the mean. 


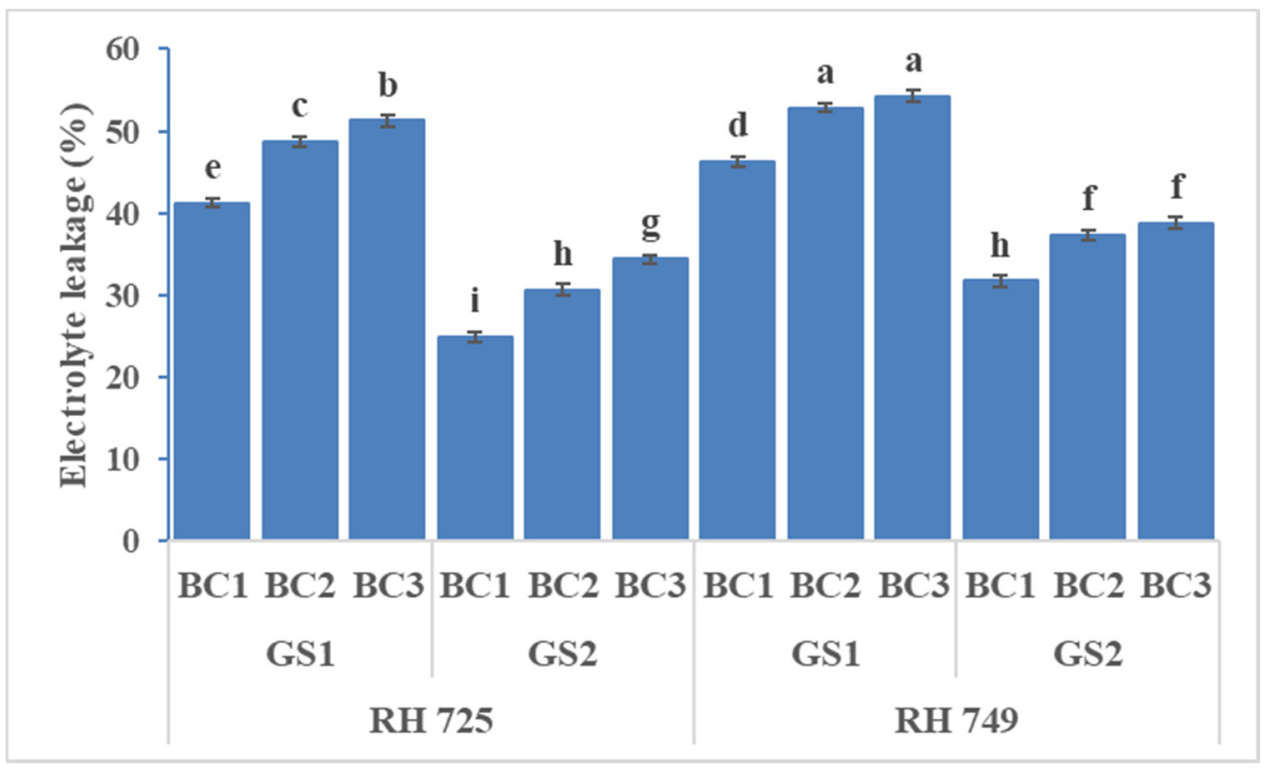

Figure 6. Comparisons of the effects of different concentrations of brassinolide sprays (BC1: control (water spray); BC2: $10 \mathrm{mg}$ BRs/L water; BC3: $20 \mathrm{mg}$ BRs/L water) on the electrolyte leakage (EL) concentration of drought-tolerant (RH 725) and drought-sensitive (RH 749) Indian mustard cultivars at the flower initiation (GS1) and 50\% flowering (GS2) stages. Columns marked by different letters indicate significant differences $(p<0.05)$ between treatments based on Duncan's multiple range test. Error bars denote the standard errors of the mean.

\subsection{Enzymatic Antioxidants}

Three-way ANOVA revealed statistical significant effects of cultivar (C), growth stage (GS), brassinolide concentration (BC), and their interaction on SOD and CAT, whereas only the individual factors had significant effects on POX (Table 1). Brassinolide at two concentrations (10 and $20 \mathrm{mg} / \mathrm{L}$ ), when applied to the plant, enhanced the activity of antioxidative enzymes (SOD, CAT, and POX) to a significant extent, but the tolerant cultivar (RH 725) showed significantly higher $(p<0.05)$ activities over the growth stages. However, all of the enzyme activities were increased significantly-particularly at the 50\% flowering stage. The tolerant cultivar RH 725 exhibited the highest enzymatic activities (SOD, POX, and CAT) as compared to the sensitive cultivar RH 749 at the $50 \%$ flowering stage. Brassinolide $(20 \mathrm{mg} / \mathrm{L})$ significantly enhanced the SOD, CAT, and POX activity by $31.73,22.80$, and $45.07 \%$ at the flower initiation stage and $36.92,27.86$, and $48.12 \%$ at the $50 \%$ flowering stage, respectively, in comparison to their controls in drought-tolerant $\mathrm{RH}$ 725, while this increase was less in the drought-sensitive cultivar RH 749 (Figures 7-9). 


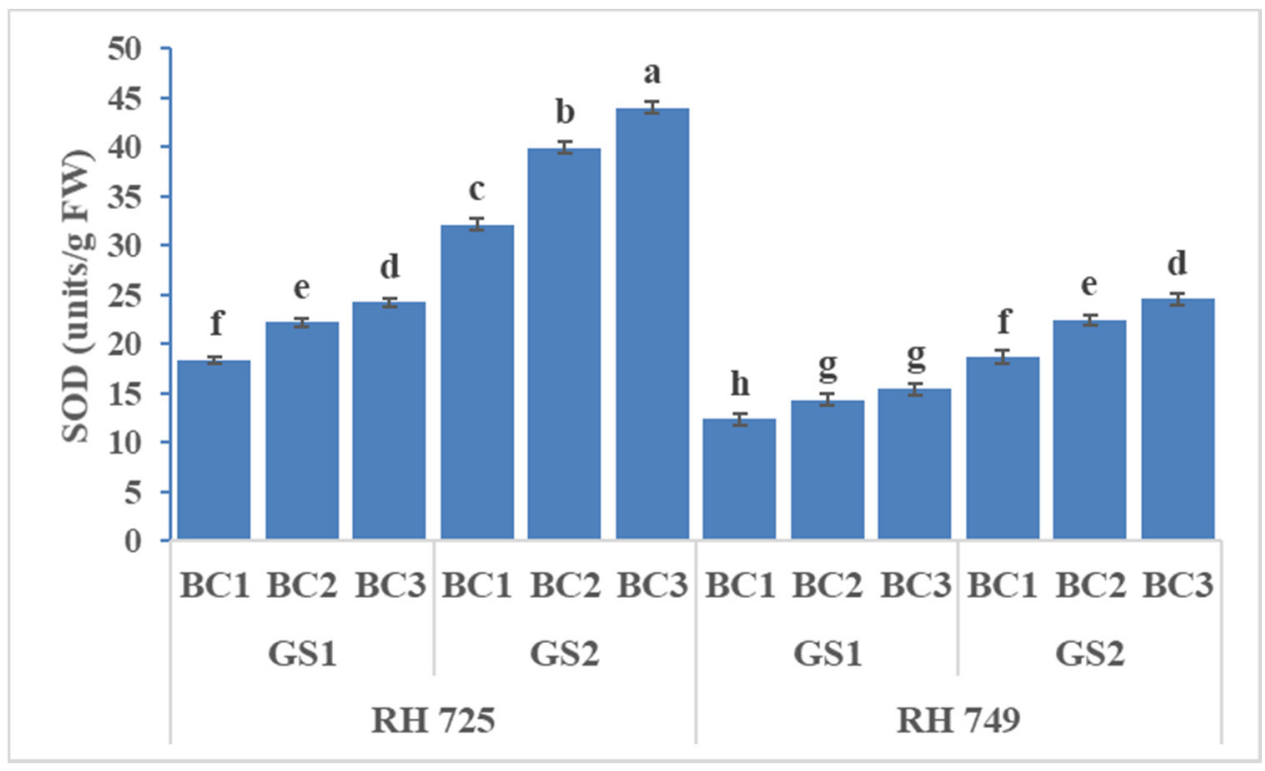

Figure 7. Comparisons of the effects of different concentrations of brassinolide sprays (BC1: control (water spray); BC2: $10 \mathrm{mg}$ BRs/L water; BC3: $20 \mathrm{mg}$ BRs/L water) on the superoxide dismutase (SOD) activity of drought-tolerant (RH 725) and drought-sensitive (RH 749) Indian mustard cultivars at the flower initiation (GS1) and 50\% flowering (GS2) stages. Columns marked by different letters indicate significant differences $(p<0.05)$ between treatments based on Duncan's multiple range test. Error bars denote the standard errors of the mean.

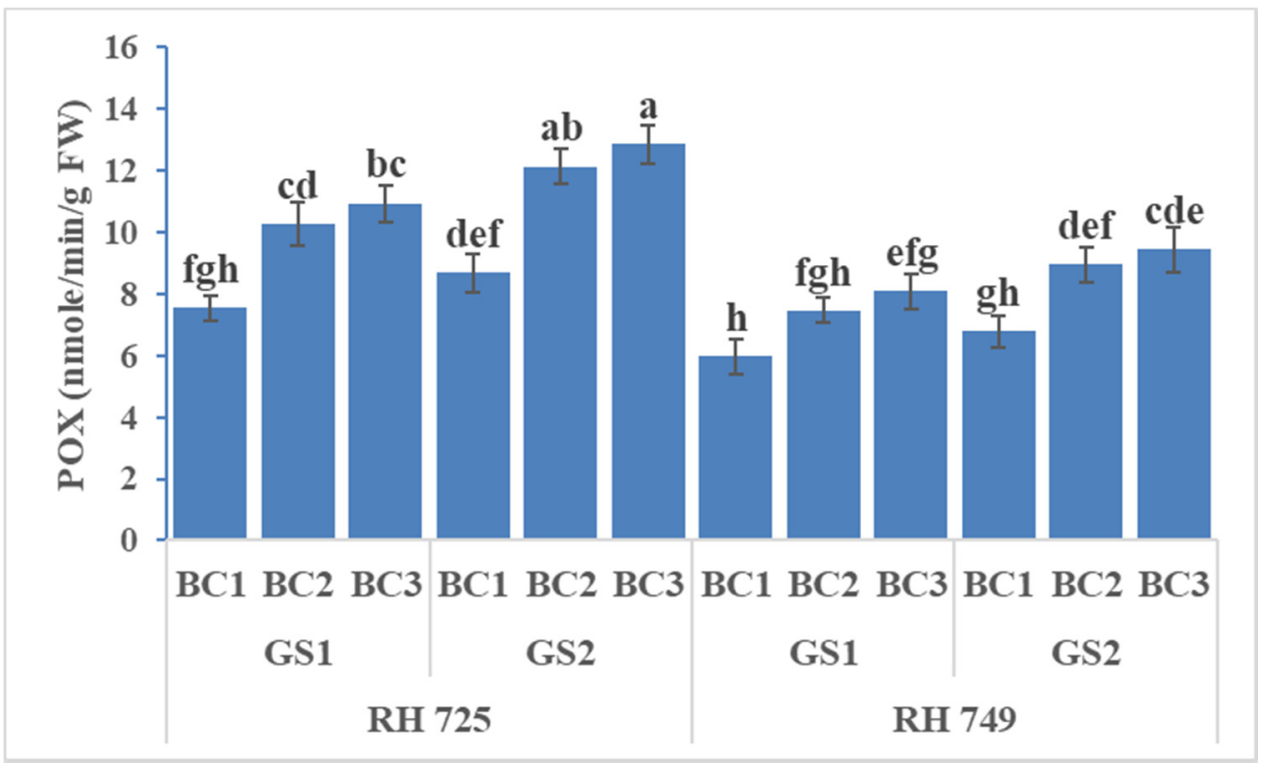

Figure 8. Comparisons of the effects of different concentrations of brassinolide sprays (BC1: control (water spray); BC2: $10 \mathrm{mg}$ BRs/L water; BC3: $20 \mathrm{mg}$ BRs/L water) on the peroxidase (POX) activity of drought-tolerant (RH 725) and drought-sensitive (RH 749) Indian mustard cultivars at the flower initiation (GS1) and 50\% flowering (GS2) stages. Columns marked by different letters indicate significant differences $(p<0.05)$ between treatments based on Duncan's multiple range test. Error bars denote the standard errors of the mean. 


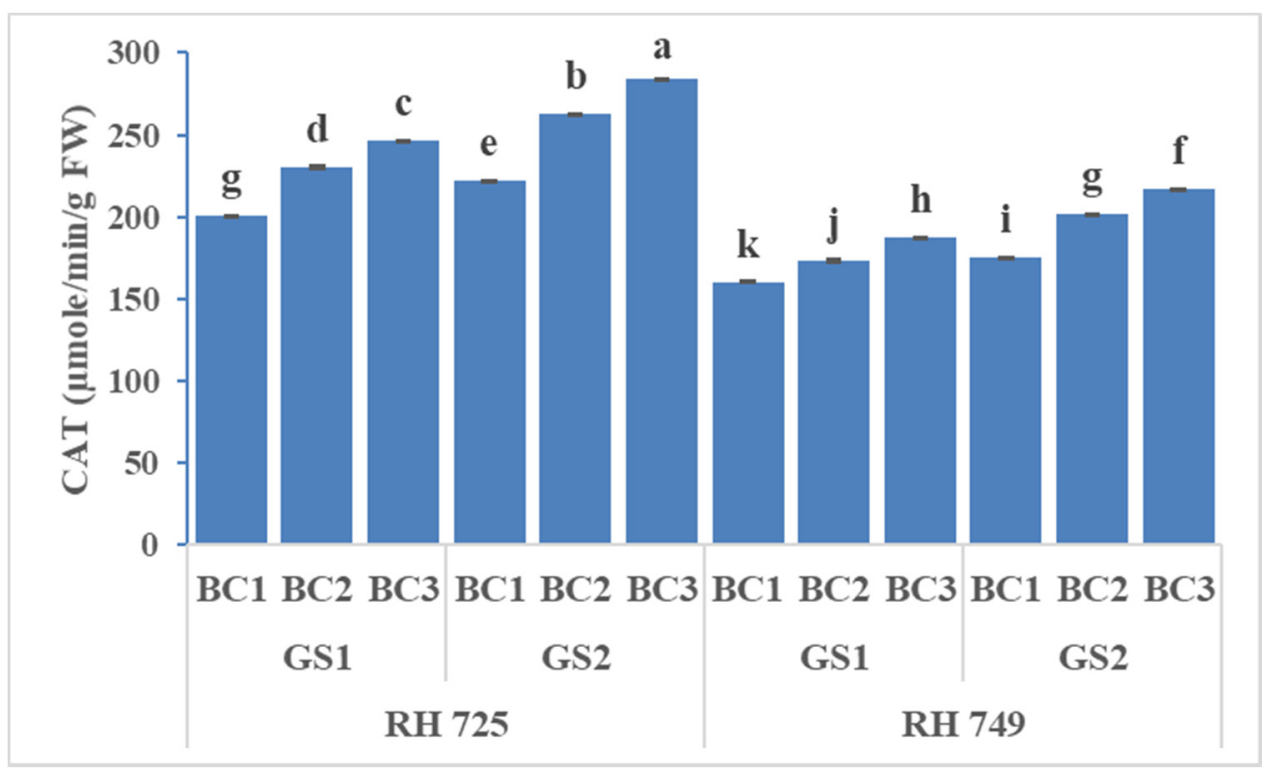

Figure 9. Comparisons of the effects of different concentrations of brassinolide sprays (BC1: control (water spray); BC2: $10 \mathrm{mg}$ BRs/L water; BC3: $20 \mathrm{mg}$ BRs/L water) on the catalase (CAT) activity of drought-tolerant (RH 725) and drought-sensitive (RH 749) Indian mustard cultivars at the flower initiation (GS1) and 50\% flowering (GS2) stages. Columns marked by different letters indicate significant differences $(p<0.05)$ between treatments based on Duncan's multiple range test. Error bars denote the standard errors of the mean.

\subsection{Non-Enzymatic Antioxidants}

ANOVA showed significant effects of cultivar, growth stage, and brassinolide concentration on all three non-enzymatic antioxidants, while their interactions-viz., $\mathrm{C} \times \mathrm{GS}$, $\mathrm{C} \times \mathrm{BC}$, and GS $\times \mathrm{BC}$-were significant for ascorbic acid only (Table 1). It is evident from Figures 10-12 that foliar application of brassinolide (10 and20 mg/L) significantly increased the non-enzymatic attributes in both cultivars, but this increase was more pronounced in the tolerant cultivar RH 725 as compared to RH 749,with increases in the levels of carotenoids, ascorbic acid, and proline (at $20 \mathrm{mg} / \mathrm{L}$ ) of $27.04,49.63$, and $40.91 \%$ at the flower initiation stage and $41.55,64.11$, and $45.22 \%$ at the $50 \%$ flowering stage, respectively, over their respective controls in $\mathrm{RH} 725$. Of the two concentrations of brassinolide and two stages of plant growth studied, $20 \mathrm{mg} / \mathrm{L}$ of brassinolide and the $50 \%$ flowering stage showed the greatest response in RH 725; this increase was less significant in the sensitive cultivar RH 749. 


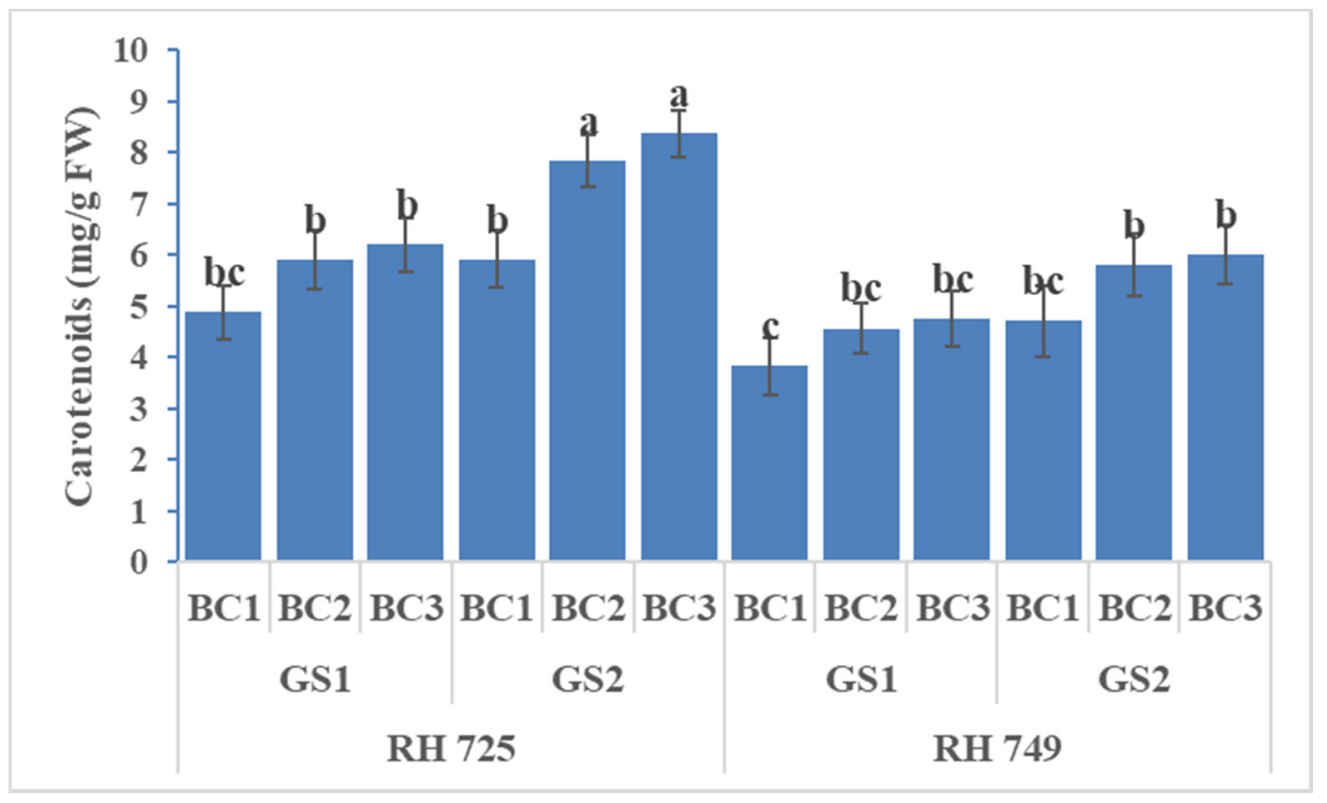

Figure 10. Comparisons of the effects of different concentrations of brassinolide sprays (BC1: control (water spray); BC2: $10 \mathrm{mg}$ BRs/L water; BC3: $20 \mathrm{mg}$ BRs/L water) on the carotenoids content (CC) of drought-tolerant (RH 725) and drought-sensitive (RH 749) Indian mustard cultivars at the flower initiation (GS1) and 50\% flowering (GS2) stages. Columns marked by different letters indicate significant differences $(p<0.05)$ between treatments based on Duncan's multiple range test. Error bars denote the standard errors of the mean.

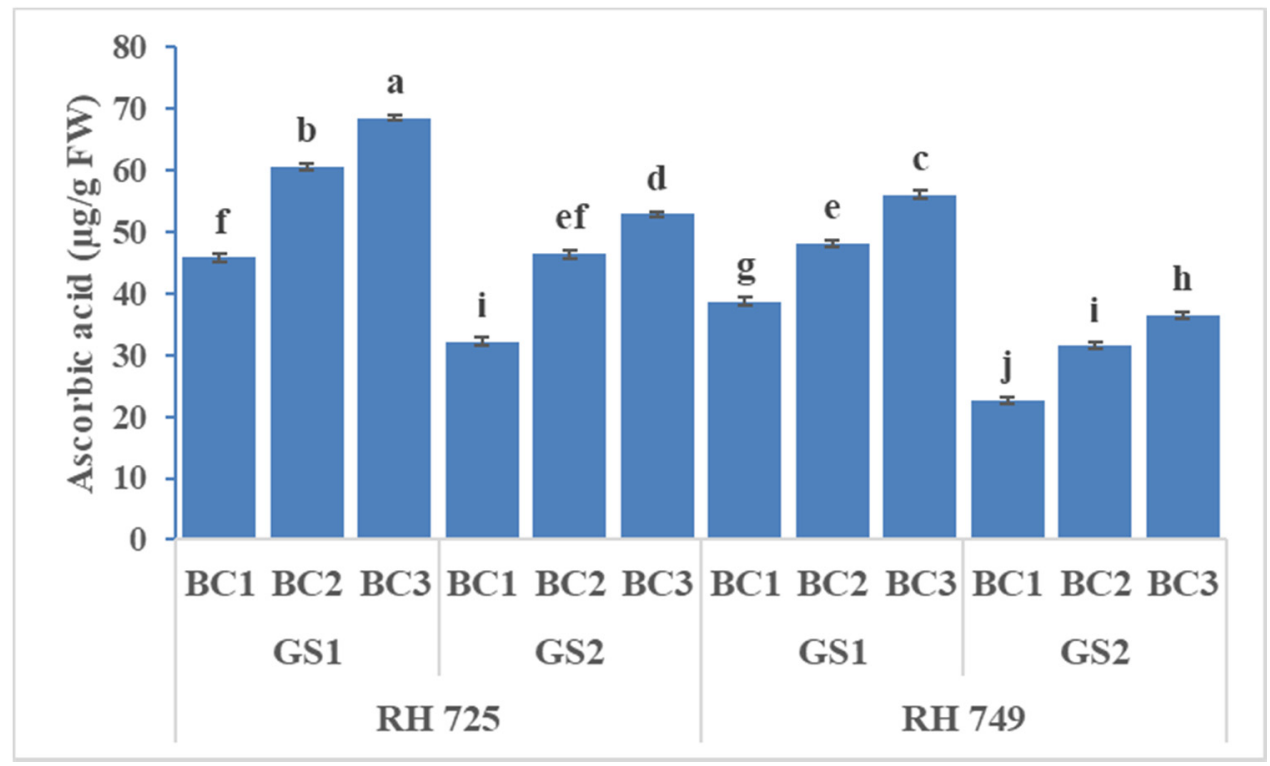

Figure 11. Comparisons of the effects of different concentrations of brassinolide sprays (BC1: control (water spray); BC2: $10 \mathrm{mg}$ BRs/L water; BC3: $20 \mathrm{mg}$ BRs/L water) on the ascorbic acid content (ASA) of drought-tolerant (RH 725) and drought-sensitive (RH 749) Indian mustard cultivars at the flower initiation (GS1) and 50\% flowering (GS2) stages. Columns marked by different letters indicate significant differences $(p<0.05)$ between treatments based on Duncan's multiple range test. Error bars denote the standard errors of the mean. 


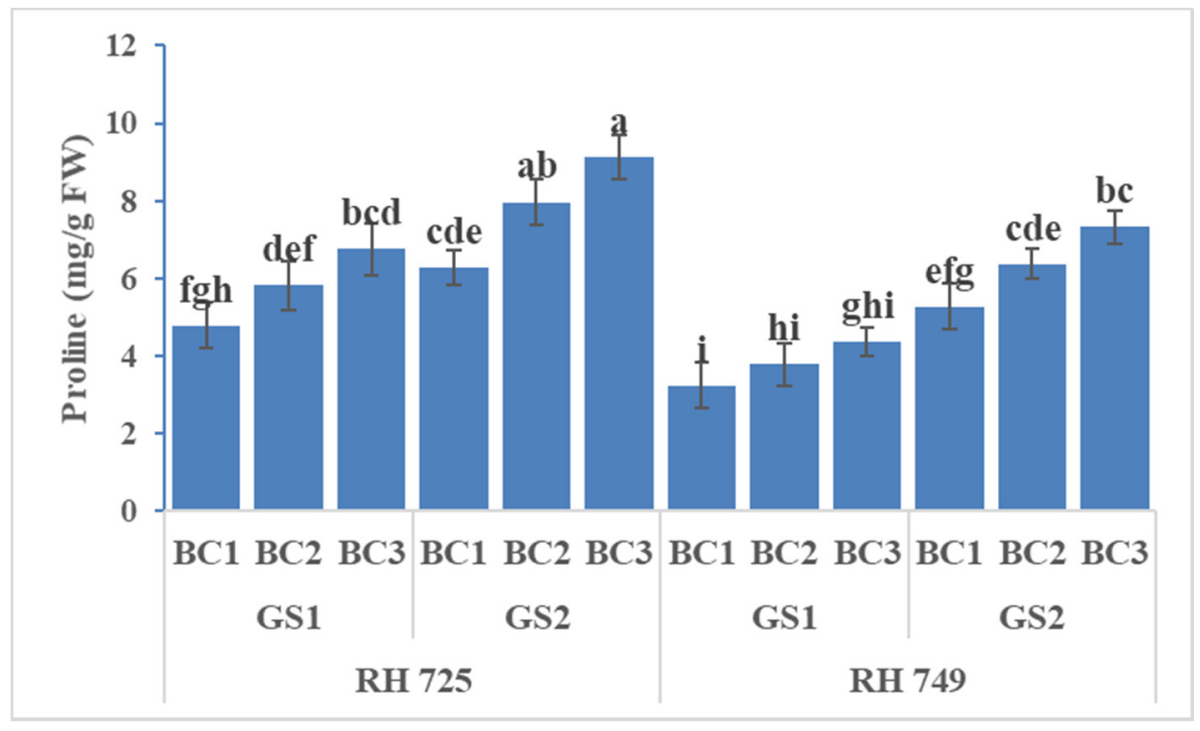

Figure 12. Comparisons of the effects of different concentrations of brassinolide sprays (BC1: control (water spray); BC2: $10 \mathrm{mg}$ BRs/L water; BC3: $20 \mathrm{mg}$ BRs/L water) on the proline content (PRO) of drought-tolerant (RH 725) and drought-sensitive (RH 749) Indian mustard cultivars at the flower initiation (GS1) and 50\% flowering (GS2) stages. Columns marked by different letters indicate significant differences $(p<0.05)$ between treatments based on Duncan's multiple range test. Error bars denote the standard errors of the mean.

\subsection{Correlation Analysis among Different Parameters}

The Pearson's correlation coefficient matrix presented in Table 2 reveals the significant negative associations between both enzymatic and non-enzymatic antioxidants and oxidative stress indicators-viz., $\mathrm{H}_{2} \mathrm{O}_{2}$ and MDA - except for ascorbic acid, which showed insignificant association between $\mathrm{H}_{2} \mathrm{O}_{2}$ and MDA, while it was significant and positively correlated with EL. Moreover, both of the oxidative stress indicators- $-\mathrm{H}_{2} \mathrm{O}_{2}$ and MDAshowed a significant positive relationship with one another. The EL, which is the most important oxidative stress indicator, showed a significant negative association with SOD only. Proline content and all physiological parameters-i.e., stomatal conductance, photosynthetic rate, and transpiration rate-were positively correlated with all of the enzymatic antioxidants, while they were negatively associated with all oxidative stress indicators except for electrolyte leakage, which showed a significant negative association with transpiration rate only.

Table 2. Pearson's product-moment correlation matrix between different physio-biochemical parameters evaluated during the present study.

\begin{tabular}{|c|c|c|c|c|c|c|c|c|c|c|c|c|}
\hline Variables & SOD & POX & CAT & $\mathrm{CC}$ & ASA & PRO & $\mathrm{H}_{2} \mathrm{O}_{2}$ & MDA & EL & SC & PR & TR \\
\hline SOD & 1.000 & 0.864 ** & $0.911^{* *}$ & 0.960 ** & 0.091 & $0.920 * *$ & $-0.909 * *$ & $-0.644^{*}$ & -0.640 * & $0.948 * *$ & $0.903 * *$ & $0.857^{* *}$ \\
\hline POX & & 1.000 & $0.974^{* *}$ & $0.962 * *$ & 0.494 & $0.901 * *$ & $-0.981 * *$ & $-0.873 * *$ & -0.220 & 0.945 ** & $0.955^{* *}$ & $0.739 * *$ \\
\hline CAT & & & 1.000 & $0.963 * *$ & 0.442 & $0.916^{* *}$ & $-0.969 * *$ & $-0.811^{* *}$ & -0.338 & $0.983^{* *}$ & $0.950 * *$ & $0.743^{* *}$ \\
\hline CC & & & & 1.000 & 0.263 & $0.957 * *$ & $-0.978^{* *}$ & $-0.801 * *$ & -0.455 & $0.970 * *$ & $0.959 * *$ & $0.856^{* *}$ \\
\hline ASA & & & & & 1.000 & 0.118 & -0.355 & -0.481 & 0.657 * & 0.332 & $0.388^{* *}$ & -0.172 \\
\hline PRO & & & & & & 1.000 & $-0.953 * *$ & $-0.824^{* *}$ & -0.537 & $0.941^{* *}$ & $0.927^{* *}$ & $0.943^{* *}$ \\
\hline $\mathrm{H}_{2} \mathrm{O}_{2}$ & & & & & & & 1.000 & $0.874^{* *}$ & 0.353 & $-0.957^{* *}$ & $-0.960 * *$ & $-0.832^{* *}$ \\
\hline MDA & & & & & & & & 1.000 & 0.025 & $-0.774 * *$ & $-0.854^{* *}$ & $-0.711^{* *}$ \\
\hline EL & & & & & & & & & 1.000 & -0.434 & -0.304 & $-0.666^{* *}$ \\
\hline SC & & & & & & & & & & 1.000 & $0.970 * *$ & $0.806^{* *}$ \\
\hline PR & & & & & & & & & & & 1.000 & $0.817^{* *}$ \\
\hline TR & & & & & & & & & & & & 1.000 \\
\hline
\end{tabular}

** Significant at $p \leq 0.01 ;{ }^{*}$ significant at $p \leq 0.05$; SOD: superoxide dismutase; PX: peroxidase; CAT: catalase; CC: carotenoids content; ASA: ascorbic acid content; PRO: proline content; $\mathrm{H}_{2} \mathrm{O}_{2}$ : hydrogen peroxide content; MDA: malondialdehyde content; EL: electrolyte leakage; SC: stomatal conductance; PR: photosynthetic rate; TR: transpiration rate. 


\section{Discussion}

Analysis of variance showed significant effects of cultivar, growth stage, brassinolide, and their interactions on most of the studied traits, indicating that drought tolerance in Indian mustard is a cultivar- and growth-stage-specific but brassinolide-responsive trait. Similar patterns of results were obtained in many previous studies [31-35]. This indicates that the drought-tolerant cultivar RH 725 is more responsive to brassinolide, and has the capacity to cope with drought-induced oxidative stress and detoxify the oxidative stress indicators by significantly elevating both the non-enzymatic and enzymatic antioxidants. Nevertheless, drought-tolerant RH 725 also has the capacity to improve the physiological processes-viz., stomatal conductance, photosynthetic rate, and transpiration rate-in order to maintain better physiology of the plant as compared to sensitive RH 749. The foliar application of brassinolide enhanced the levels of both enzymatic and non-enzymatic antioxidants, and caused decreased production of oxidative stress indicators (MDA, $\mathrm{H}_{2} \mathrm{O}_{2}$, and EL). However, we found that the physio-biochemical contents/activities in the leaves depend on the genotype of the cultivar. The drought-tolerant cultivar RH 725 had significantly higher levels of both enzymatic and non-enzymatic antioxidants, and higher physiological parameters, along with lower levels of oxidative stress indicators as compared to the drought-sensitive cultivar RH 749. This indicates that the drought-tolerant cultivar-particularly at the $50 \%$ flowering stage-is more responsive to exogenous application of BRs in terms of mitigating drought stress, compared to the sensitive cultivar. Similar results were also reported previously in many crops, including maize [36], sunflowers, [37]; tomatoes, [38], and chickpeas [39].

Brassinosteroids are attractive as original regulators in plants because of their ability to enhance cells in two ways: to provide defense, and to promote growth [40]. Tolerance provided by $\mathrm{BR}$ treatment is mediated via the provoked expression of genes involved in defense, regulation, antioxidant responses, and the production of high levels of $\mathrm{H}_{2} \mathrm{O}_{2}$, which results from enhanced activity of NADPH oxidase [41]. Brassinosteroids regulate the activity of antioxidative enzymes in the cells where ROS production is very high [42] These results are consistent with the findings of Behnamnia et al. [18], who reported significant augmentation in SOD, CAT, and POX activity in Lycopersicon esculentum with the application of brassinolide under drought stress. Similar effects of brasinosteroids were also observed in maize [43], soybeans [44], wheat [45], and Indian mustard [16]. These findings consistent with those of Kumari and Thakur [46], who reported that BRs could regulate antioxidant enzymes such as superoxide dismutase, catalase, peroxidase, etc., in plants under different stress conditions.

Non-enzymatic antioxidants such as carotenoids, ascorbic acid, and proline play a vital rolein the metabolism of plants, by shielding them from stress conditions [47]. Plants produce the carotenoids, which are natural pigments and are involved in photoprotection and photosynthesis. Under drought conditions, carotenoids increase significantly. Ascorbic acid is one of the most powerful antioxidants, which scavenge harmful free radicals and other ROS [48]. Brassinolide was reported to increase the contents of ascorbic acid and total carotenoids in seedlings of drought-resistant (PAN 6043) and drought-sensitive (SC 701) cultivars of Zea mays under water stress [43]. Plants accrue low-molecular-mass compounds, such as proline [49], which acts as a non-enzymatic antioxidant that is well known to stabilize the sub-cellular structures of proteins and cell membranes, scavenging free radicals and buffering redox potential under various stress conditions. Proline also acts as a molecular chaperone that preserves the integrity of proteins and boosts the activity of various enzymes during stressful conditions [50]. Among the different compatible solutes, proline is the only molecule that protects the plants against singlet oxygen and damage induced by free radicals resulting from various stresses [51]. It has also been reported previously that BRs propel the expression of proline biosynthetic genes [52]. High proline content in plants under water stress is frequently observed in several plant species $[53,54]$.

The product of membrane peroxidation is the thiobarbituric-acid-reactive substance malondialdehyde (MDA), which is used as a direct marker of membrane damage and lipid 
peroxidation. Reactive oxygen species attack the majority of the sensitive macromolecules in cells under various environmental stresses, interfering with their function. Drought stress resulted in an increase in MDA accumulation in the leaves of Indian mustard [53]. It was reported that level of lipid peroxidation induced by biotic stresses-such as oxygen deficiency [55], drought stress [56], and heat [57]—could be decreased by treatment with BRs. The results of the present study are consistent with earlier findings that the level of lipid peroxidation in Brassica juncea leaves was augmented during drought stress, and it was significantly minimized by BR application. Hydrogen peroxide is produced in the cells under normal as well as a wide range of stressful conditions, such as drought, chilling, UV irradiation, exposure to intense light, wounding, and intrusion by pathogens; it can generate singlet oxygen upon reaction with superoxide anions $/ \mathrm{HOCl}$, and it can degrade certain heme proteins to release iron ions, so it is considered to increase membrane permeability by degrading membrane lipids [58]. Therefore, it is important that $\mathrm{H}_{2} \mathrm{O}_{2}$ be scavenged rapidly by the antioxidative defense system.

Leaf membrane damage was determined by measurement of electrolyte leakage (EL), as described by Valentovic et al. [59]. Electrolyte leakage decreased considerably in Curcuma alismatifolia when subjected to water-deficit stress [60]. This is an indicator of a drought-tolerance mechanism in the species via the maintenance of membrane integrity and reduction in electrolyte leakage. The exposure of the plants to drought stress resulted in an increase in electrolyte leakage, which was mitigated by spraying with brassinolide. Houimli et al. [61] observed that exogenous application of brassinolide resulted in a significant reduction in electrolyte leakage under salt stress. Similarly, Coban and Baydar [62] reported a significant reduction in electrolyte leakage in maize, along with improved morphometric parameters, when brassinolide was applied.

Stomatal conductance, photosynthetic rate, and transpiration rate are important characteristics describing plants' water relations [63]. These are inter-related traits of plants that play major roles under stress conditions. In the present study, there were significant increases in stomatal conductance, photosynthetic rate, and transpiration rate with brassinolide spraying under drought stress. Similar increases in these parameters due to BR application have previously been observed in tomatoes, wheat, and cucumbers under both normal conditions and environmental stresses [41,45,57]. Brassinosteroids are also known to activate the key enzymes of photosynthesis, i.e., rubisco [64] and carbonic anhydrase [65]. The assimilation of $\mathrm{CO}_{2}$ in the Calvin cycle is increased by high carbonic anhydrase activity, which is primarily ascribed to efficient functioning of rubisco [66], consequently improving the net photosynthetic rate and related attributes.

Furthermore, the significant negative association of both enzymatic and non-enzymatic antioxidants with oxidative stress indicators, along with their positive correlation with physiological parameters, again confirmed the role of the antioxidant defense system in mitigating the negative effects of drought stress. However, a further analysis of this phenomenon is certainly needed.

\section{Conclusions}

The present investigation found that both concentrations of brassinolide (10 and $20 \mathrm{mg} / \mathrm{L}$ ) improved the plants' efficiency via different physio-biochemical amendments. However, with the $20 \mathrm{mg} / \mathrm{L}$ brassinolide spray at the $50 \%$ flowering stage, various physiobiochemical attributes showed a more emphatic response in RH 725 than in RH 749. Enhancement of the antioxidative system with improved antioxidative enzyme activity and accumulation of proline may strengthen the plants' ability to combat different stress conditions. Moreover, the drought-tolerant cultivar (RH 725) was superior in term of antioxidant defense system, as compared with the sensitive cultivar RH 749. Indeed, this could be one of the reasons for the former's higher drought tolerance. Understanding the mechanisms of drought tolerance in Indian mustard will make it possible for plant breeders and plant physiologists to develop specific techniques to mitigate the adverse effects of drought, and to maximize Indian mustard crop production. 
Supplementary Materials: The following are available online at https:/ / www.mdpi.com/article/10 $.3390 /$ horticulturae7110514/s1, Supplementary Table S1: Weekly averaged rainfall data during the crop season of 2018-19 at CCS Haryana Agricultural University, Hisar.

Author Contributions: Conceptualization, N.K. and R.A.; methodology, N.K., R.A. and B.R.; validation, M.J., S.A. and N.K.; software, M.S., resources, R.A., investigation, N.N. and N.K.; data curation, M.S., N.N. and K.M.; writing—original draft, N.N.; writing—review and editing, M.S., N.K. and A.S. All authors have read and agreed to the published version of the manuscript.

Funding: This research was supported by Oilseeds Section, Department of Genetics and Plant Breeding, CCS Haryana Agricultural University, Hisar, India. [C (b) PB-3-ICAR].

Institutional Review Board Statement: Not applicable.

Informed Consent Statement: Not applicable.

Data Availability Statement: The data used for the analysis in this study are available within the article, while the datasets used or analyzed during the current study are available from the corresponding author upon reasonable request.

Acknowledgments: The first author is highly grateful to HOS, Oilseeds Section, Department of Genetics and Plant Breeding, CCS Haryana Agricultural University, Hisar, for providing the necessary facilities throughout her M.Sc. research work.

Conflicts of Interest: The authors declare no conflict of interest.

\section{References}

1. Singh, M.; Avtar, R.; Lakra, N.; Hooda, E.; Singh, V.K.; Bishnoi, M.; Kumari, N.; Punia, R.; Kumar, N.; Choudhary, R.R. Genetic and Proteomic Basis of Sclerotinia Stem Rot Resistance in Indian Mustard [Brassica juncea (L.) Czern \& Coss.]. Genes 2021, 12, 1784.

2. Norton, R.; Burton, W.; Salisbury, P. Canola quality Brassica juncea for Australia. In Proceeding of 4th International Crop Science Congress, Gosford, Australia, 26 September-1 October 2004; p. 5.

3. Mahmood, T.; Ashraf, M.; Shahbaz, M. Does exogenous application of glycine-betaine as a pre-sowing seed treatment improve growth and regulate some key physiological attributes in wheat plants grown under water deficit conditions? Pak. J. Bot. 2009, 41, 1291-1302.

4. Gill, S.S.; Tuteja, N. Reactive oxygen species and antioxidant machinery in abiotic stress tolerance in crop plants. Plant Physiol. Biochem. 2010, 48, 909-930. [CrossRef]

5. Anjum, N.A.; Sofo, A.; Scopa, A.; Roychoudhury, A.; Gill, S.S.; Iqbal, M.; Lukatkin, A.S.; Pereira, E.; Duarte, A.C.; Ahmad, I. Lipids and proteins-Major targets of oxidative modifications in abiotic stressed plants. Environ. Sci. Pollut. Res. 2014, 22, 4099-4121. [CrossRef] [PubMed]

6. $\quad$ Singh, M.; Avtar, R.; Pal, A.; Punia, R.; Singh, V.K.; Bishnoi, M.; Singh, A.; Choudhary, R.R.; Mandhania, S. Genotype-Specific Antioxidant Responses and Assessment of Resistance Against Sclerotinia sclerotiorum Causing Sclerotinia Rot in Indian Mustard. Pathogens 2020, 9, 892. [CrossRef] [PubMed]

7. Nayyar, H.; Gupta, D. Differential sensitivity of C3 and C4 plants to water deficit stress: Association with oxidative stress and antioxidants. Environ. Exp. Bot. 2006, 58, 106-113. [CrossRef]

8. El-Mashad, A.A.A.; Mohamed, H.I. Brassinolide alleviates salt stress and increases antioxidant activity of cowpea plants (Vigna sinensis). Protoplasma 2012, 249, 625-635. [CrossRef] [PubMed]

9. Foyer, C.; Noctor, G. Oxygen processing in photosynthesis: Regulation and signaling. New Phytol. 2000, 146, 359-388. [CrossRef]

10. Tripathy, B.C.; Oelmüller, R. Reactive oxygen species generation and signaling in plants. Plant Signal. Behav. 2012, 7, 1621-1633. [CrossRef] [PubMed]

11. Mittler, R. Oxidative stress, antioxidants and stress tolerance. Trends Plant Sci. 2002, 7, 405-410. [CrossRef]

12. Arora, N.; Bhardwaj, R.; Sharma, P.; Arora, H.K. 28-Homobrassinolide alleviates oxidative stress in salt-treated maize (Zea mays L.) plants. Braz. J. Plant Physiol. 2008, 20, 153-157. [CrossRef]

13. Hayat, S.; Hasan, S.A.; Hayat, Q.; Ahmad, A. Brassinosteroids protect Lycopersicon esculentum from cadmium toxicity applied as shotgun approach. Protoplasma 2010, 239, 3-14. [CrossRef]

14. Bajguz, A.; Hayat, S. Effects of brassinosteroids on the plant responses to environmental stresses. Plant Physiol. Biochem. 2009, 47, 1-8. [CrossRef] [PubMed]

15. Hasan, S.A.; Hayat, S.; Ali, B.; Ahmad, A. 28-homobrassinolide protects chickpea (Cicer arietinum) from cadmium toxicity by stimulating antioxidants. Environ. Pollut. 2008, 151, 60-66. [CrossRef] [PubMed]

16. Fariduddin, Q.; Khanam, S.; Hasan, S.A.; Ali, B.; Hayat, S.; Ahmad, A. Effect of 28-homobrassinolide on the drought stress-induced changes in photosynthesis and antioxidant system of Brassica juncea L. Acta Physiol.Plant 2009, 31, 889-897. [CrossRef]

17. Ali, B.; Hayat, S.; Ahmad, A. 28-Homobrassinolide ameliorates the saline stress in chickpea (Cicer arietinum L.). Environ. Exp. Bot. 2007, 59, 217-223. [CrossRef] 
18. Behnamnia, M.; Kalantari, K.M.; Ziaie, J. The effects of brassinosteroid on the induction of biochemical changes in Lycopersicon esculentum under drought stress. Turk. J. Botany 2009, 33, 417-428.

19. Zhang, M.; Zhai, Z.; Tian, X.; Duan, L.; Li, Z. Brassinolide alleviated the adverse effect of water deficits on photosynthesis and the antioxidant of soybean (Glycine max L.). Plant Growth Regul. 2008, 56, 257-264. [CrossRef]

20. Shen, X.Y.; Dai, J.Y.; Hu, A.C.; Gu, W.L.; He, R.Y.; Zheng, B. Studies on physiological effects of brassinolide on drought resistance in maize. J. Shenyang Agric. Univ. 1990, 21, 191-195.

21. Gill, M.B.; Cai, K.; Zhang, G.; Zeng, F. Brassinolide alleviates the drought-induced adverse effects in barley by modulation of enzymatic antioxidants and ultrastructure. Plant Growth Regul. 2017, 82, 447-455. [CrossRef]

22. Silva, F.V.D.F.; Mendes, B.D.S.; Rocha, M.D.S.; Brito, J.F.D.; Beltrão, N.E.D.M.; Sofiatti, V. Photosynthetic pigments and gas exchange in castor bean under conditions of above the optimal temperature and high $\mathrm{CO}_{2}$. Acta Sci. Agron. 2015, 37, 331-337. [CrossRef]

23. Beauchamp, C.; Fridovich, I. Superoxide dismutase: Improved assays and an assay applicable to acrylamide gels. Anal. Chem. 1971, 44, 276-287. [CrossRef]

24. Sinha, A.K. Calorimetric assay of catalase. Anal. Chem. 1972, 47, 389-395.

25. Shannon, L.M.; Key, E.; Law, J.Y. Peroxidase isoenzymes from horse reddish roots: Isolation and physical properties. J. Biol. Chem. 1966, 241, 2166-2172. [CrossRef]

26. Hiscox, J.D.; Israelstam, G.F. A method for the extraction of chlorophyll from leaf tissue without maceration. Can. J. Bot. 1979, 57, 1332-1334. [CrossRef]

27. Roe, J.H. Chemical determination of ascorbic dehydroascorbic and diketogluconic acids. Methods Biochem. Anal. 1954, 1, 115-139.

28. Bates, L.S.; Waldren, R.P.; Teare, I.D. Rapid determination of free proline for water-stress studies. Plant Soil 1973, 39, 205-207. [CrossRef]

29. Heath, R.L.; Packer, L. Photoperoxidation in isolated chloroplasts: I. Kinetics and stoichiometry of fatty acid peroxidation. Arch. Biochem. Biophys. 1968, 125, 189-198. [CrossRef]

30. Gong, J.R.; Zhao, A.F.; Huang, Y.M.; Zhang, X.S.; Zhang, C.L. Water relations, gas exchange, photochemical efficiency, and peroxidative stress of four plant species in the Heihe drainage basin of northern China. Photosynthetica 2006, 44, 355-364. [CrossRef]

31. Ali, M.A.; Jabran, K.; Awan, S.I.; Abbas, A.; Zulkiffal, M.; Acet, T.; Farooq, J.; Rehman, A. Morpho-physiological diversity and its implications for improving drought tolerance in grain sorghum at different growth stages. Aust. J. Crop Sci. 2011, 5, 311-320.

32. Kumari, A.; Avtar, R.; Kumari, N.; Jattan, M.; Rani, B. Screening for drought tolerance in Indian mustard (Brassica juncea L.) genotypes based on yield contributing characters and physiological parameters. J. Oilseed Brassica 2019, 10, 1-7.

33. Anjum, S.A.; Wang, L.C.; Farooq, M.; Hussain, M.; Xue, L.L.; Zou, C.M. Brassinolide application improves the drought tolerance in maize through modulation of enzymatic antioxidants and leaf gas exchange. J. Agron. Crop Sci. 2011, 197, 177-185. [CrossRef]

34. Dehghan, M.; Balouchi, H.; Yadavi, A.; Zare, E. Improve wheat (Triticum aestivum) performance by brassinolide application under different irrigation regimes. S. Afr. J. Bot. 2020, 130, 259-267. [CrossRef]

35. Chen, L.; Yang, H.; Fang, Y.; Guo, W.; Chen, H.; Zhang, X.; Dai, W.; Chen, S.; Hao, Q.; Yuan, S.; et al. Overexpression of GmMYB14 improves high-density yield and drought tolerance of soybean through regulating plant architecture mediated by the brassinosteroid pathway. Plant Biotechnol. J. 2021, 19, 702-716. [CrossRef] [PubMed]

36. Tůmová, L.; Tarkowská, D.; Řehořová, K.; Marková, H.; Kočová, M.; Rothová, O.; Čečetka, P.; Holá, D. Drought-tolerant and drought-sensitive genotypes of maize (Zea mays L.) differ in contents of endogenous brassinosteroids and their drought-induced changes. PLoS ONE 2018, 13, e0197870. [CrossRef]

37. Ghasemi, M.; Jahanbin, S.; Latifmanesh, H.; Farajee, H.; Mirshekari, A. Effect of brassinolide foliar application on some physiological and agronomic characteristics of sunflower (Helianthus annuus L.) under drought stress conditions. J. Crop Prod. 2021, 14, 31-48.

38. Jangid, K.K.; Dwivedi, P. Physiological and biochemical changes by nitric oxide and brassinosteroid in tomato (Lycopersicon esculentum Mill.) under drought stress. Acta Physiol Plant. 2017, 39, 73. [CrossRef]

39. Verma, J.; Kakralya, B.L.; Jakhar, M.L. Effect of Brassinolide on physiological aspects of Chick pea (Cicer arietinum L.) under drought conditions. J. Plant Sci. Res. 2012, 28, 151-155.

40. Sun, Y.; Fan, X.Y.; Cao, D.M.; Tang, W.; He, K.; Zhu, J.Y. Integration of brassinosteroid signal transduction with the transcription network for plant growth regulation in Arabidopsis. Dev. Cell. 2010, 19, 765-777. [CrossRef] [PubMed]

41. Xia, X.J.; Huang, L.F.; Zhou, Y.H.; Mao, W.H.; Shi, K.; Wu, J.X.; Asami, T.; Chen, Z.; Yu, J.Q. Brassinosteroids promote photosynthesis and growth by enhancing activation of Rubisco and expression of photosynthetic genes in Cucumis sativus. Planta 2009, 230, 1185-1196. [CrossRef] [PubMed]

42. Ashraf, M.; Akram, N.A.; Arteca, R.N.; Foolad, M.R. The physiological, biochemical and molecular roles of brassinosteroids and salicylic acid in plant processes and salt tolerance. Crit. Rev. Plant Sci. 2010, 29, 162-190. [CrossRef]

43. Li, L.; Van Staden, J.; Jager, A.K. Effects of plant growth regulators on the antioxidant system in seedlings of two maize cultivars subjected to water stress. Plant Growth Regul. 1998, 25, 81-87. [CrossRef]

44. Zhang, Y.; Luo, Y.X.; Hou, H.; Jiang, Q.; Chen and Tang, R.H. Chilling acclimation induced changes in the distribution of $\mathrm{H}_{2} \mathrm{O}_{2}$ and antioxidant system of strawberry leaves. Agric. J. 2008, 3, 286-291. 
45. Shahbaz, M.; Ashraf, M.; Athar, H. Dose exogenous application of 24-epibrassinolide ameliorate salt induced growth inhibition in wheat (Triticum aestivum L.)? Plant Growth Regul. 2008, 55, 51-64. [CrossRef]

46. Kumari, S.; Thakur, A. The Effects of Water Stress and Brassinosteroid on Apple Varieties. Int. J. Econ. Plants 2019, 6, 1-6. [CrossRef]

47. Tyagi, A.; Santha, I.M.; Mehta, S.L. Effect of water stress on proline content and transcript levels in Lathyrus sativus. Indian J. Biochem. Biophys. 1999, 36, 207-210.

48. Smirnoff, N. Ascorbate biosynthesis and function in photoprotection. Philos. Trans. R Soc. Lond. B Biol. Sci. 2000, 355, 1455-1464. [CrossRef]

49. Bajji, M.; Lutts, S.; Kinet, J.M. Water deficit effects on solute contribution to osmotic adjustment as a function of leaf ageing in three durum wheat (Triticum durum Desf.) cultivars performing differently in arid conditions. Plant Sci. J. 2001, 160, 669-681. [CrossRef]

50. Szabados, L.; Savoure, A. Proline: A multifunctional amino acid. Trends Plant Sci. 2010, 15, 89-97. [CrossRef] [PubMed]

51. Alyemeni, M.N.; Al-Quwaiz, S.M. Effect of 28-homobrassinolide on the performance of sensitive and resistant varieties of Vigna radiata. Saudi J. Biol. Sci. 2016, 23, 698-705. [CrossRef]

52. Ozdemir, F.; Bor, M.; Demiral, T.; Turkan, I. Effects of 24- epibrassinolide on seed germination, seedling growth, lipid peroxidation, proline content and antioxidative system of rice (Oryza sativa L.) under salinity stress. Plant Growth Regul. 2004, 42, 203-211. [CrossRef]

53. Kumari, N.; Avtar, R.; Kumari, A.; Sharma, B.; Rani, B.; Sheoran, R.K. Antioxidative response of Indian mustard subjected to drought stress. J. Oilseed Brassica 2018, 9, 40-44.

54. Rani, B.; Madan, S.; Pooja, K.S.; Sharma, K.D.; Kumari, N.; Kumar, A. Mitigating the effect of drought stress on yield in wheat (Triticum aestivum) using arbuscular mycorrhiza fungi (Glomus mosseae). Indian J. Agric. Sci. 2018, 88, 95-100.

55. Ershova, A.N.; Khripach, V.A. Effect of epibrassinolide on lipid peroxidation in Pisum sativum at normal aeration and under oxygen deficiency. Russ. J. Plant Physiol. 1996, 43, 750-752.

56. Robinson, J.M.; Bunce, J.A. Influence of Drought-Induced Water Stress on Soybean and Spinach Leaf Ascorbate-Dehydro ascorbate level and Redox Status. Int. J. Plant Sci. 2000, 161, 271-279. [CrossRef]

57. Ogweno, J.O.; Song, X.S.; Shi, K.; Hu, W.H.; Mao, W.H.; Zhou, Y.H.; Nogués, S. Brassinosteroids alleviate heat-induced inhibition of photosynthesis by increasing carboxylation efficiency and enhancing antioxidant systems in Lycopersicon esculentum. J. Plant Growth Regul. 2008, 27, 49-57. [CrossRef]

58. Krieger-Liszkay, A. Singlet oxygen production in photosynthesis. J. Exp. Bot. 2005, 56, 337-346. [CrossRef]

59. Valentovic, P.; Luxova, M.; Kolarovic, L.; Gasparikova, O. Effect of osmotic stress on compatible solutes content, membrane stability and water relations in two maize cultivars. Plant Soil Environ. 2006, 52, 186-191. [CrossRef]

60. Jungklang, J.; Saengnil, K.; Uthaibutra, J. Effects of water-deficit stress and paclobutrazol on growth, relative water content, electrolyte leakage, proline content and some antioxidant changes in Curcuma alismatifolia Gagnep. cv. Chiang Mai Pink. Saudi J. Biol. Sci. 2017, 24, 1505-1512. [CrossRef]

61. Houimli, S.I.M.; Denden, M.; Mouhandes, B.D. Effects of 24-epibrassinolide on growth, chlorophyll, electrolyte leakage and proline by pepper plants under NaCl-stress. Eur. Asian J. Biosci. 2010, 4, 96-104. [CrossRef]

62. Coban, O.; Baydar, N.G. Brassinosteroid effects on some physical and biochemical properties and secondary metabolite accumulation in peppermint (Mentha piperita L.) under salt stress. Ind. Crop. Prod. 2016, 86, 251-258. [CrossRef]

63. Farooq, M.; Aziz, T.; Wahid, A.; Lee, D.J.; Siddique, K.H. Chilling tolerance in maize: Agronomic and physiological approaches. Crop Pasture Sci. 2009, 60, 501-516. [CrossRef]

64. Yu, J.Q.; Huang, L.F.; Hu, W.H.; Zhou, Y.H.; Mao, W.H.; Ye, S.F.; Nogue's, S. A role for brassinosteroids in the regulation of photosynthesis in Cucumis sativus. J. Exp. Bot. 2004, 55, 1135-1143. [CrossRef] [PubMed]

65. Yusuf, M.; Fariduddin, Q.; Hayat, S.; Hasan, S.A.; Ahmad, A. Protective responses of 28-homobrssinolide in cultivars of Triticumaestivum with different levels of nickel. Arch. Environ. Contam. Toxicol. 2011, 60, 68-76. [CrossRef] [PubMed]

66. Bajguz, A.; Asami, T. Suppression of Wolffiaarrhiza growth by brassinazole, an inhibitor of brassinosteroid biosynthesis and its restoration by endogenous 24-epibrassinolide. Phytochemistry 2005, 66, 1787-1796. [CrossRef] [PubMed] 